OPEN@ACCESS

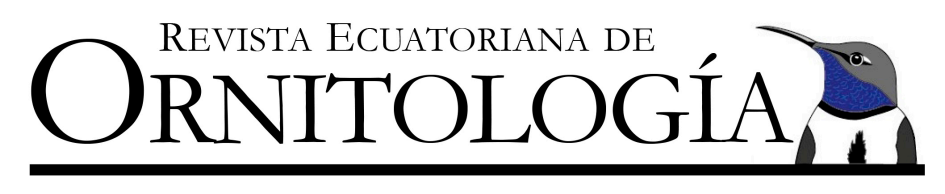

NOTAS DE CAMPO/FIELD NOTES

\title{
Gavilán de Harris Parabuteo unicinctus depredando una serpiente
}

\author{
Héctor Cadena-Ortiz \\ Pajareando Ando Ecuador \& Instituto Nacional de Biodiversidad, calle Rumipamba 341 y Av. de Los Shyris, 17-07-8976, Quito, Ecuador. \\ E-mail:fercho cada@yahoo.es \\ Editado por/Edited by: Harold Greeney \\ Recibido/Received: 04 Abril 2020. Aceptado/Accepted: 28 Septiembre 2020 \\ Publicado en línea/Published online: 14 Diciembre 2020
}

Registrar eventos de depredación en la naturaleza es poco común, y el conocimiento de ítems alimenticios específicos es útil para vislumbrar la ecología trófica de las especies (Fierro-Calderón et al., 2006). Para el Gavilán de Harris Parabuteo unicinctus existen reportes de alimentación basada principalmente en mamíferos, y se asume como raro que consuma serpientes (Dwyer \& Bednarz, 2020).

En un camino vecinal poco transitado y rodeado de parches de vegetación ribereña, sembríos y casas dispersas en Taura (-2,3107, -79,7289; 3 m s.n.m.), provincia de Guayas, Ecuador, observé y fotografié el 17 de julio de 2019, a las 08h30, un individuo adulto de Parabuteo unicinctus depredando una serpiente (Fig. 1). El reptil medía $c .70 \mathrm{~cm}$ de longitud y $c .2 \mathrm{~cm}$ de diámetro, era de color verde con el vientre más claro; probablemente se trataba de un adulto de Leptophis ahaetulla (Colubridae). El gavilán sujetaba con las garras la parte media de la serpiente, que aun se movía. Con el pico desgarraba trozos de carne con piel y los ingería. Durante todo el tiempo de observación, el gavilán mantuvo las alas abiertas asentadas en el suelo, cubriendo a la presa, dando la espalda a un Gavilán Sabanero Buteogallus meridionalis que vocalizaba desde un árbol cercano. Después de c. 20 min de desgarrar a la presa, a un movimiento del observador, el individuo de $P$. unicinctus tomó la parte anterior de la serpiente, ya partida en dos, y voló.

Se ha reportado consumo de serpientes por $P$. unicinctus, basado en presas llevadas a nidos, pero no hay una descripción de su captura (Jaksić et al., 1980; Salvador, 2012; Dwyer \& Bednarz, 2020). Por su parte, el comportamiento de cubrir la presa con las alas mientras la consume, proceso descrito como natural en las rapaces para evitar que el robo de la presa (Jones, 2001), fue al parecer dirigido al individuo cercano de $B$. meridionalis, ya que existen reportes previos de ataques a $P$. unicinctus por parte de rapaces de mayor tamaño (Jiménez \& Jaksic, 1993).

\section{REFERENCIAS}

Dwyer, J. F. \& Bednarz, J. C. (2020). Harris's Hawk (Parabuteo unicinctus), version 1.0. In: Poole, A. F. (Ed.). Birds of the World. Ithaca, USA: Cornell Lab of Ornithology. DOI: https://doi.org/10.2173/bow.hrshaw.01

Fierro-Calderón, K., Estela, F. A., \& Chacón-Ulloa, P. (2006). Observaciones sobre las dietas de algunas aves de la Cordillera Oriental de Colombia a partir del análisis de contenidos estomacales. Ornitología Colombiana, 4, 6-15. URL: https://asociacioncolombianadeornitologia.org/wp-content/uploads/revista/oc4/Dietas.pdf

Jaksić, F. M., Yáñez, J. L., \& Schlatter, R. P. (1980). Prey of the Harris' Hawk in central Chile. Auk, 97(1), 196198. URL: https://www.jstor.org/stable/4085822

Jiménez, J. E. \& Jaksic, F. M. (1993). Observations on the comparative behavioral ecology of Harris Hawk in Chile. Journal of Raptor Research, 27, 143-148. URL: https://sora.unm.edu/sites/default/files/journals/jrr/ v027n03/p00143-p00148.pdf 
Jones, M. P. (2001). Behavioral aspects of captive birds of prey. Veterinary Clinics of North America: Exotic Animal Practice, 4(3), 613-632. DOI: https://doi.org/10.1016/S1094-9194(17)30026-9

Salvador, S. A. (2012). Dieta del Gavilán mixto (Parabuteo u. unicinctus) en Villa María, Córdoba, Argentina. Nuestras Aves, 57, 21-23. URL: https://www.avesargentinas.org.ar/revista-nuestras-aves-n\%C2\%B0-57-2012

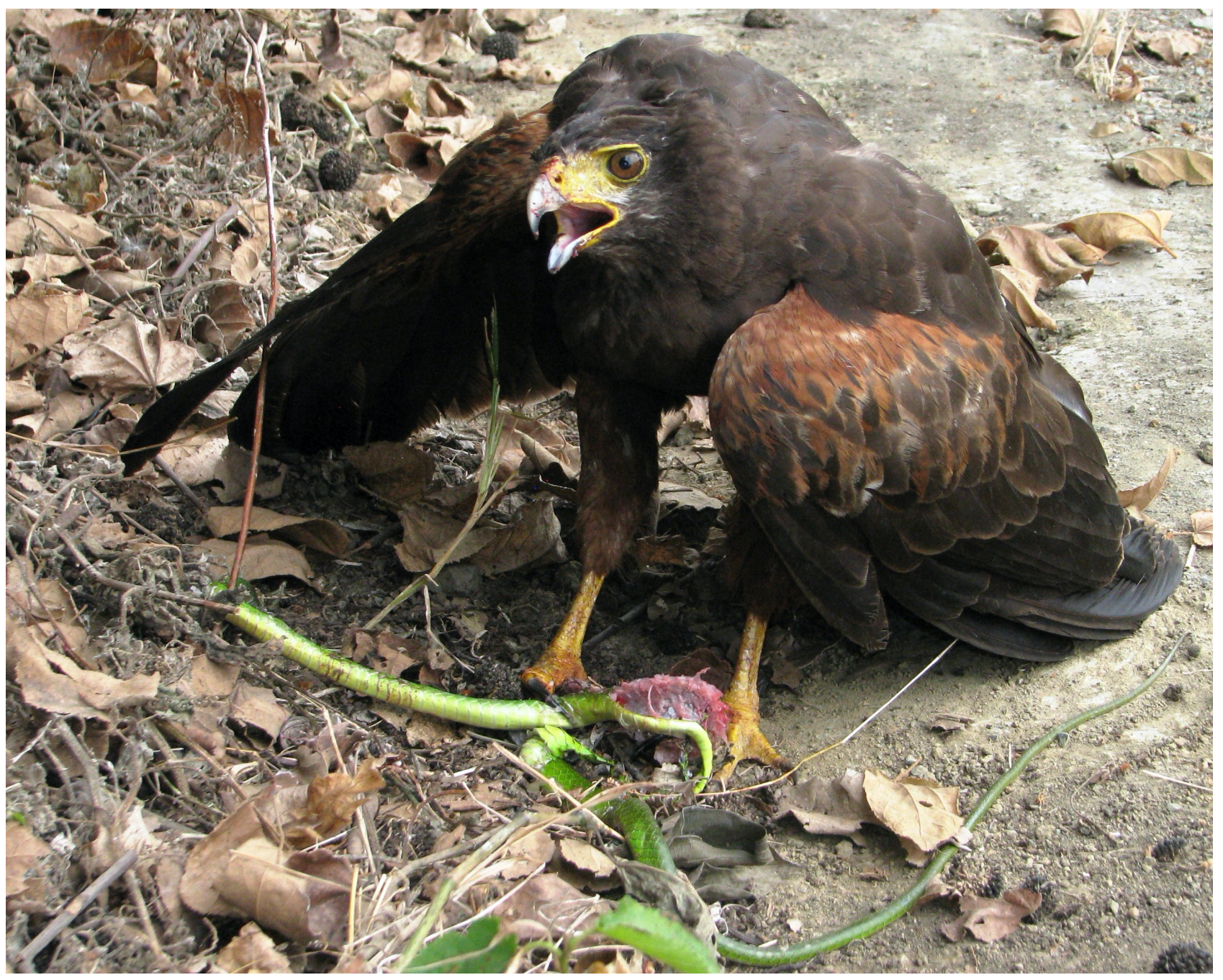

Figura 1: Gavilán de Harris Parabuteo unicinctus depredando una serpiente (cf. Leptophis ahaetulla) en Taura, Guayas, el 17 de julio de 2019 (Héctor Cadena). 